\begin{tabular}{c} 
International Journal of Engineering \& Technology, 7 (4.26) (2018) 279-284 \\
International Journal of Engineering \& Technology \\
SPC \\
Website: www.sciencepubco.com/index.php/IJET \\
Research paper \\
\hline
\end{tabular}

\title{
Numerical Models for Hydraulic Refracturing on Vertical Oil Wells
}

\author{
Vladimir Bratov ${ }^{1,2}$ \\ ${ }^{I}$ Peter the Great St. Petersburg Polytechnic University, Russia, 195251, St.Petersburg, Polytechnicheskaya, 29 \\ ${ }^{2}$ Institute for Problems of Mechanical Engineering of the Russian Academy of Sciences, Russia, 199178, St. Petersburg, V.O., \\ Bolshoj pr., 61
}

\begin{abstract}
The paper presents an approach for simulation of refracturing treatment on vertical oil wells. The model is accounting for filtration of hydraulic fracturing fluid through the proppant packed inside the crack formed during previous hydraulic fracturing treatments. The simulations provide a possibility to estimate history of stress intensity factor appearing at the tip of the existing crack once the time profile of pressure within the wellbore is given. Introducing critical value of the stress intensity factor for the fractured media, time-to-fracture initiation (after pressure increase start) can be estimated and compared to instance of fracture event registered in real conditions. Also, the possibility of fracture reorientation through formation of new fractures at the region adjacent to the wellbore is studied.
\end{abstract}

Keywords: hydraulic fracturing, fracturing fluid, oil production, oil production increment

\section{Introduction}

The technology of hydraulic fracturing refers to the creation a highly conductive fracture in the target reservoir under the impact of a fluid supplied under pressure to provide the flow of a fluid being produced (natural gas, water, condensate, oil or their mixture) to the bottom of the well $[11,12]$.

After hydraulic fracturing, the flow rate usually jumps or a pressure drawdown drop occurs $[13,14]$.

Hydraulic fracturing enables the "revival" of idle wells, where oil or gas no longer can be produced traditionally or when such production is no longer profitable [15].

Hydraulic fracturing is also a solution for coal seam degasification, underground gasification, etc.

Besides, this technology is currently applied to new oil reservoirs, which traditional development is unprofitable due to low production rates $[16,17]$.

This technology is also applied in shale gas production and compacted sandstone gas production [18].

Refracturing (or refrac) treatment for restimulation of oil wells previously treated utilizing hydraulic fracturing can often significantly increase oil production and result in substantial additional oil output. For that reason, refrac had become a widely spread and effective technology that is used to restore well oil production to original or even higher production rates as well as to extend a well productive life. Refrac technologies are applied to both the vertical and the horizontal wells. In many cases multiple refrac treatments are applied to a well in the course of its productive life. Unfortunately, in many cases refrac treatment is not resulting in significant (or any) oil production increment (see ex. [1-3]). In some cases, refracturing can result in well deterioration or even well permanent damage. In that connection, possibility to predict good candidate wells, promising advantageous well production increase is of a great importance for the industry. Likewise, numerical simulations, providing a possibility to predict optimal refracturing process scenario, that will lead to desired alternations of the well conditions and geometry are of a great interest [4]. All that induces the notable interest for numerical simulations of refracturing process. Simulation of hydraulic fracturing is a complicated problem solution of which, depending on the model used, requires different simplifications and assumptions. It is clear, that simulation of refracturing is a much more complicated problem involving not only the simulation of fracture, appearing in a vicinity of a loaded well (see ex. [5]). Obviously, this simulation should account for the evolution of pressure inside the crack of the initial hydraulic fracture cracks and the appearing stress field surrounding the tip of this crack followed by strength analysis. This paper presents an attempt to develop simplest model being able to predict weather the refracturing will increment the existing large crack created during previous hydraulic fracturing or that can result in formation of new fractures originating from the vicinity of the wellbore. That will require the solution of two independent problems:

a) solution searching for stressed state surrounding the tip of previously created crack, followed by strength analysis giving the moment of time when this crack is initiated under given loading conditions (given history of pressure within the wellbore).

b) Solution searching for stressed state in the vicinity of the wellbore, followed by strength analysis giving the moment of time when fractures can be initiated under given loading conditions (given history of pressure within the wellbore).

Comparison of the two solutions for the same loading history, same initial geometry, same material properties, etc., will tell which of the two fracture scenarii will take place (simulation giving smaller time-to-fracture initiation) in the corresponding case.

\section{Stressed State Surrounding the Tip of a Previously Created Crack}

Following the initiation of the refrac loading (increase of fracturing fluid pressure in the wellbore), fluid pressure is propagating inside the crack created during the initial hydraulic fracturing. This pressure is responsible for development of a stressed state, 
surrounding the crack tip. Reaching the critical state, this stressed state will result in propagation of fracture from the tip of the existing crack. The problem to be solved is to find the time at which this fracture will be initiated given the problem geometry, properties of the materials, initial stressed state and the history of pressure in the wellbore. The problem geometry is limited to simplest possible case: two symmetric rectilinear cracks originating from the wellbore. Usual sizes of hydraulic fracturing cracks vary between 50 and 200 meters. Figure 1 is giving the schematic representation for the problem of fracture initiated at the tip of the existing hydraulic fracture crack. The fracture is caused by pressure that is applied at the wellbore.

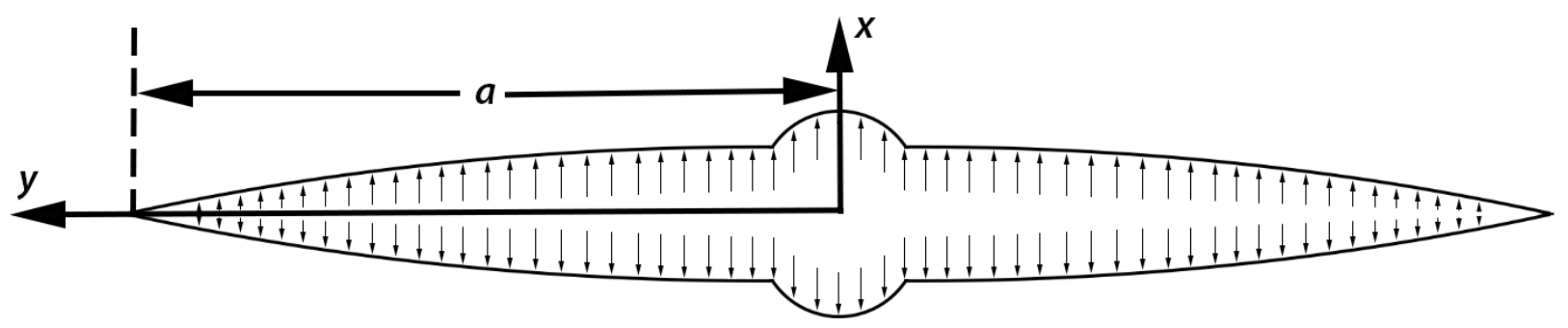

Fig, 1; Schematic representation for the problem of refracture initiated at a tip of a crack formed during previous hydraulic fracturing

The problem can be divided into a problem for forces (or stresses) acting on the faces of the cracks and the problem for the stressed state in the bulk of the rock with special interest for the region surrounding the crack tip.

Distribution of pressure on the crack faces can be found supposing time dependent pressure is known within the wellbore by solving the problem of filtration of fracturing fluid through proppant kept inside the crack. The problem is schematically presented in figure 2 .

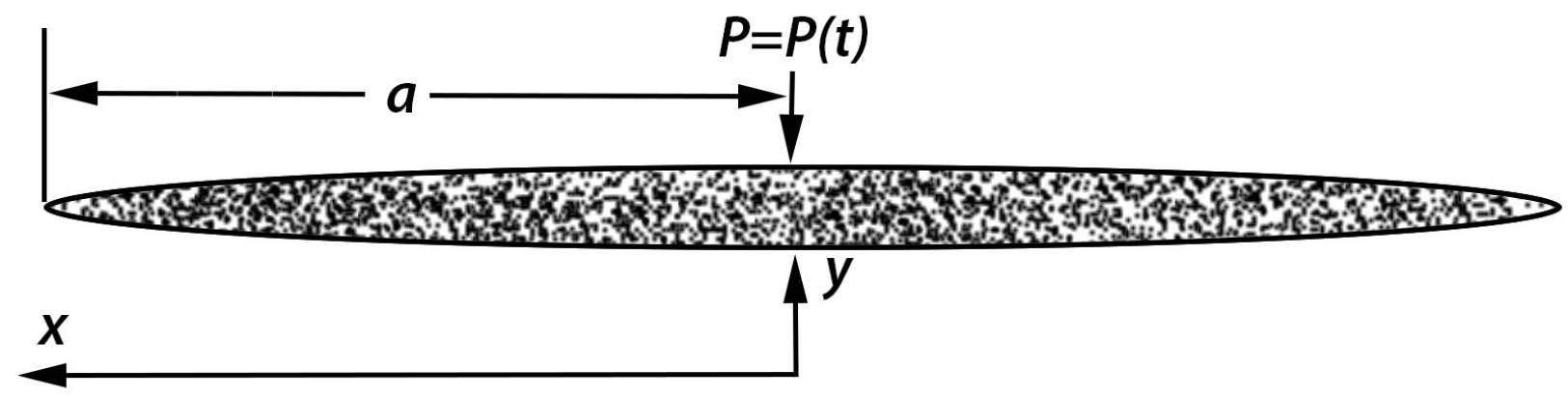

Fig. 2: Schematic representation of the problem for filtration of fracturing fluid through proppant.

Since it can be supposed that the crack opening is small comparing to the crack length, the problem can be solved as a 1-dimensional problem, assuming the solution to be not significantly dependent on the $y$-coordinate (see figure 2). The aim is to find the time and $x$ coordinate dependency of pressure for given $P(t)$ - time dependent pressure at $x=0$, corresponding to the position of the wellbore. Obviously, the estimations of time-dependent pressure distribution can only be received as a solution of transient equations for unsteady filtration. This solution can be received as a solution of continuity equation, representing the mass conservation law:

$$
\frac{\partial \mathrm{m} \rho}{\partial \mathrm{t}}+\operatorname{div} \rho \overrightarrow{\mathrm{u}}=0
$$

and a filtration law given by Darcy's law coupling the filtration speed and the pressure in the media:

$$
\overrightarrow{\mathrm{u}}=-\frac{\mathrm{k}}{\mu} \operatorname{grad} \mathrm{p},
$$

where $p$ is the pressure, $t$ stands for time, $k$ is permeability, $\mu$ is the viscosity of the fracturing fluid, $c$ stands for porosity, $\rho$ is mass density and $\vec{u}$ is the fluid filtration speed. For 1-dimensional case and for quasi-uncompressible fluid, supposing the relative changes of density $\rho$ and porosity $m$ to be small, the filtration law and the continuity equations yield equation (see ex. [6]), formally coinciding with the thermal conductivity equation:

$$
\frac{\partial \mathrm{p}}{\partial \mathrm{t}}=\varkappa \frac{\partial^{2} \mathrm{p}}{\partial \mathrm{x}^{2}}
$$

This equation is often called the equation of piezo-conductivity with coefficient $x$ called the coefficient of piezo-conductivity. $x$ is depending both on the properties of the filtrated fluid and the properties of the filtrating material. Equation 3 should be supplemented with initial and boundary conditions. In our case:

-suppose for initial time $(t=0)$ there is no pressure created by the liquid inside the crack (or this pressure is small comparing to pressures created at refracturing):

$$
\left.\mathrm{p}(\mathrm{x})\right|_{\mathrm{t}=0}=0,
$$

which gives the initial conditions for the problem. It is supposed that time dependency of pressure within the wellbore is a given function:

$$
\left.p(t)\right|_{x=0}=P(t)
$$

giving the Dirichlet boundary condition at the wellbore.

-the tips of the existing crack are impermeable and (i.e. filtration speed is equal to zero at these points):

$$
\left.\mathrm{u}\right|_{\mathrm{x}=\mathrm{a}, \mathrm{x}=-\mathrm{a}}=0 .
$$

Taking use of the Darcy's law one can easily get:

$$
\left.(\operatorname{grad} p)\right|_{x=a, x=-a}=\left.\frac{\partial p}{\partial x}\right|_{x=a, x=-a}=0,
$$

giving the Neumann boundary condition at the tips of the crack. 
Thus, (3-7) is stating a problem with solution giving the distribution of pressure on the crack faces for any time subsequent to hydraulic loading initiation. This model is not accounting for possible leakoffs of the fluid into the rock. Carter's law (see [7]) can be used to estimate the specific leak-off speed of the fracturing fluid into the rock:

$$
u_{L}=\frac{C_{L}}{\sqrt{t-t_{\text {exp }}}}
$$

where $C_{L}$ is the fluid loss coefficient that should be evaluated empirically, $t$-is the current time and $t_{\exp }$ is the time when the liquid reached the given point. In our case $t_{\text {exp }}=0$ for all of the points along the crack. Taking the leak-offs into consideration will change equations 1 and 3 :

$$
\begin{aligned}
& \frac{\partial \mathrm{m} \rho}{\partial \mathrm{t}}+\operatorname{div} \rho \overrightarrow{\mathrm{u}}=-u_{L} \\
& \frac{\partial \mathrm{p}}{\partial \mathrm{t}}=\varkappa \frac{\partial^{2} \mathrm{p}}{\partial \mathrm{x}^{2}}-\frac{\gamma_{L}}{\sqrt{t}}
\end{aligned}
$$

Thought in some cases (i.e. for simple $P(t)$ ) the stated problem can be solved analytically utilizing variable separation method, in order to provide a possibility to simulate refrac treatment for any given $P(t)$, the problem is solved numerically utilizing finite difference method with Crank-Nicolson scheme [8]. Figure 3 is giving an example of the received dependencies of pressure along the crack. Different lines correspond to different time instances.

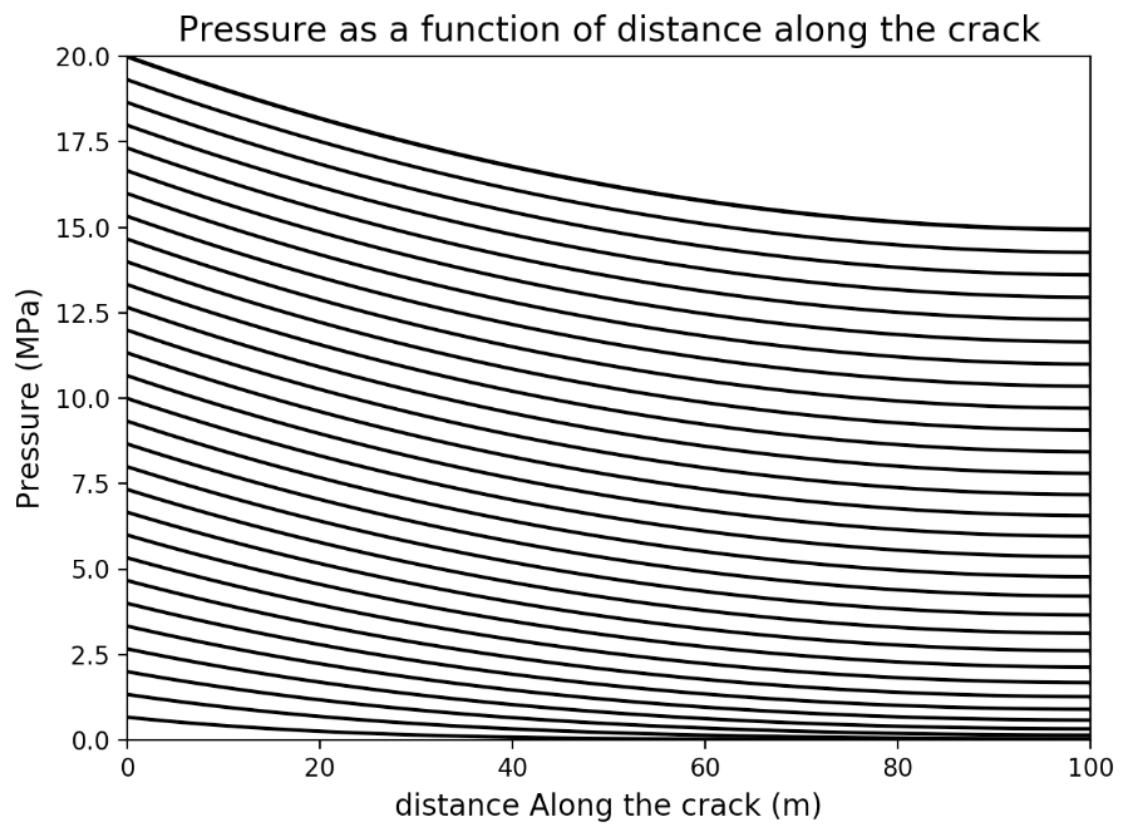

Fig. 3: Distribution of pressure along the crack for different time instance (different lines). In this case pressure in the wellbore is linearly growing with time $-\mathrm{P}(\mathrm{t})=\mathrm{dP}_{0} \mathrm{t}$.

Once the distribution of pressure on the crack faces is received as a function of time, it is possible to estimate the history of the stress intensity factor appearing at the crack tip. Assuming the behavior of rock can be described utilizing linear elastic fracture mechanics, the stress intensity factor for central crack, quasistatically loaded on its faces with distributed pressure can be received as (ex. see [910]):

$$
\begin{aligned}
& \mathrm{K}_{\mathrm{I}}=\frac{1}{\sqrt{\pi \mathrm{a}}} \int_{-\mathrm{a}}^{\mathrm{a}} n(x) \sqrt{\frac{\mathrm{a}+\mathrm{x}}{\mathrm{a}-\mathrm{x}}} \mathrm{dx} \\
& \mathrm{K}_{\mathrm{II}}=\frac{1}{\sqrt{\pi \mathrm{a}}} \int_{-\mathrm{a}}^{\mathrm{a}} \mathrm{t}(x) \sqrt{\frac{\mathrm{a}+\mathrm{x}}{\mathrm{a}-\mathrm{x}}} \mathrm{dx},
\end{aligned}
$$

where $a$ is the crack half-length, $n(x)$ and $t(x)$ are the normal and tangential components of forces applied at the crack faces and $x$ is the coordinate along the crack with the origin at the middle of the crack. Knowing the distribution of forces on the crack faces (induced either by pressure inside the crack of external forces applied - i.e. tectonic stresses), these integrals can be evaluated numerically following any suitable approach. Examples of the received $K_{\mathrm{I}}$ time dependencies for wellbore pressure applied following the Heaviside step function (suddenly applied pressure) and linearly growing pressure are presented in figure 4 .

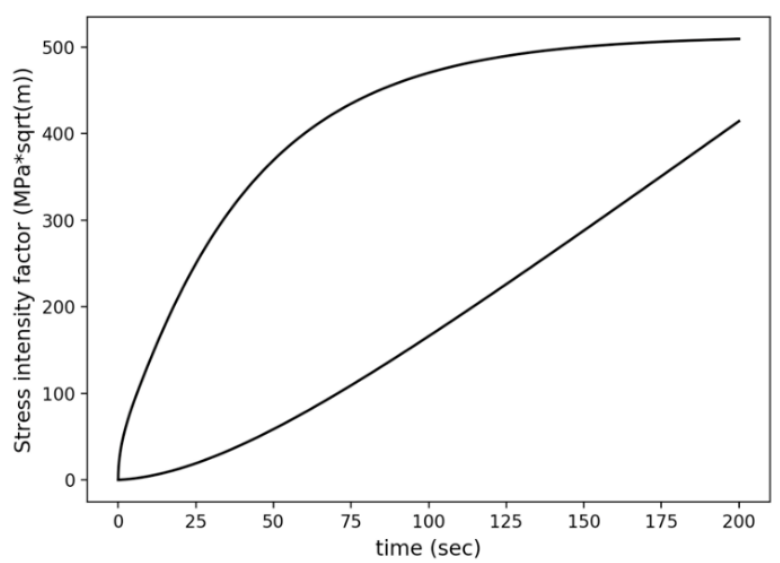

Fig. 4: Calculated time dependencies of mode I stress intensity factor in the tip of the crack for pressure with amplitude of 20MPa suddenly applied at the wellbore at $t=0$ (upper curve) and pressure at the wellbore linearly changing from $0 \mathrm{MPa}$ at $\mathrm{t}=0$ to $20 \mathrm{MPa}$ at $\mathrm{t}=200 \mathrm{sec}$ (lower curve).

As follows from the presented results, the developed approach provides a possibility to predict the history of the stress intensity factor appearing at the tip of the crack developed during previous hydraulic fracturing if the history of pressure at the wellbore and the properties of the initial crack are given along with filtration properties of media inside the crack. Should these properties be 
appended with the critical stress intensity factor for the fractured rock, that will open a possibility to predict time when the crack created during previous hydraulic fracture will initiate.

Possible properties of cracks, rock and filtration properties of proppant inside the crack are presented in table 1.

Table 1: Typical properties of materials, filtration properties of proppant inside crack and parameters of wellbore pressure history for refract treatments

\begin{tabular}{|c|c|}
\hline Permeability of packed proppant inside crack, Darcy & 100 \\
\hline & $0.03-$ \\
Leakoff coefficient, $\mathrm{cm}^{3} / \mathrm{min}^{1 / 2}$ & 0.12 \\
\hline Maximum wellbore pressure, atm & $500-800$ \\
\hline Length of existing crack, $\mathrm{m}$ & $50-200$ \\
\hline Elastic modulus of rock, GPa & $10-50$ \\
\hline
\end{tabular}
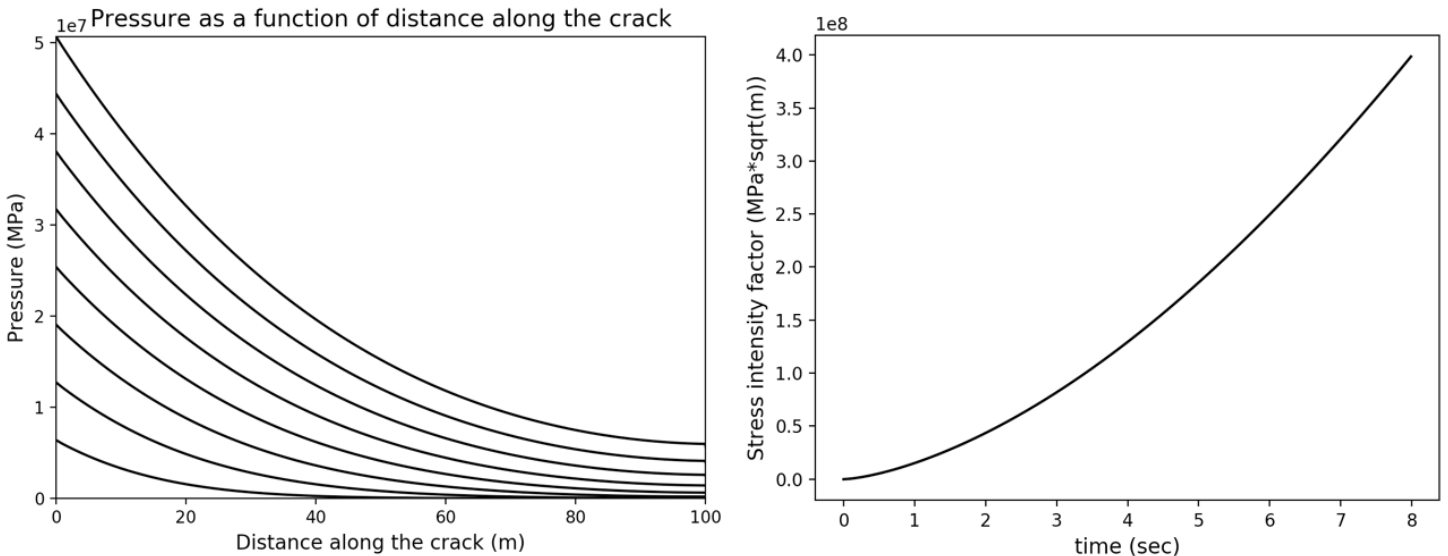

Fig. 5: Pressure distribution (left figure) and the history of stress intensity factor (right) for crack with length half span of 100 meters and linear growth of pressure within the wellbore from 0 to 500 atmospheres within 8 seconds

Introducing the critical stress intensity factor for the fractured rock material, it is possible to evaluate time to initiation of fracture at the tip of the existing crack. For the studied rock the critical value was taken to be equal to $2 * 10^{6} \mathrm{~Pa}^{*} \mathrm{M}^{-1 / 2}$, which is a typical value for sandstone. Figure 6 is giving time to fracture initiation as a function of pressure growth rate for a crack with half-span equal to $100 \mathrm{~m}$.

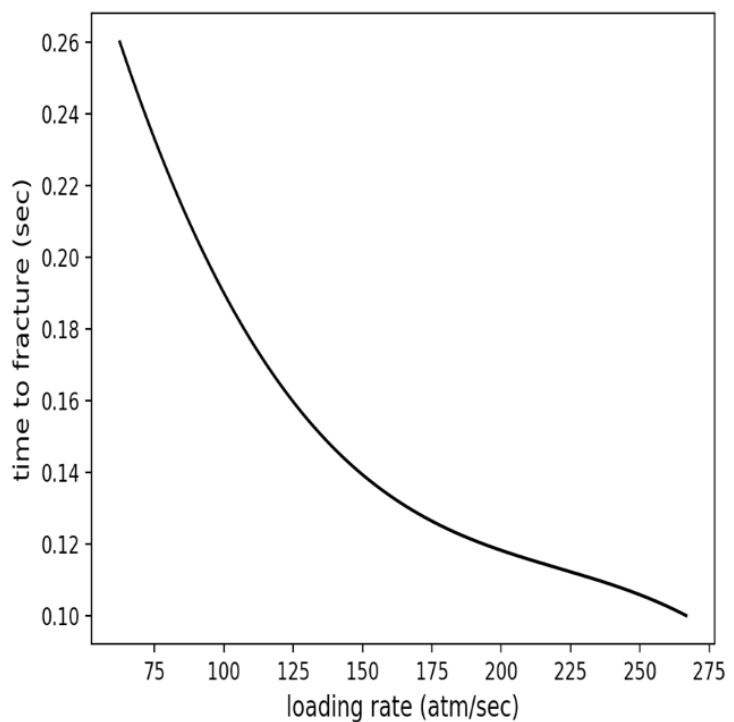

Fig. 6; Time to initiation of fracture at the tip of the crack as a function of pressure growth rate. Crack length is $100 \mathrm{~m}$.

Figure 7 is giving time to fracture initiation as a function of the initial crack length.

\begin{tabular}{|c|c|}
\hline Poisson's ratio of rock & $0.2-0.3$ \\
\hline Density of rock, $\mathrm{g} / \mathrm{cm}^{3}$ & $1.6-2.5$ \\
\hline Porosity, \% & $6-37$ \\
\hline $\begin{array}{c}\text { Tensile strength of rock (brazil test), MPa } \\
\mathrm{m}^{2} / \mathrm{s}\end{array}$ & $0.5-13$ \\
\hline $\begin{array}{c}\text { Coefficient of piezo of media inside crack, } \\
\text { conductity }\end{array}$ & 333 \\
\hline
\end{tabular}

Using the properties presented in table 1 it is possible to predict time dependent distribution of stresses as well as the histories of the stress intensity factor at the tip of the crack. Figure 5 presents the received history of pressure distribution and the history of stress intensity factor for crack with half-span of 100 meters and linear growth of pressure within the wellbore from 0 to 500 atmospheres within 8 seconds.

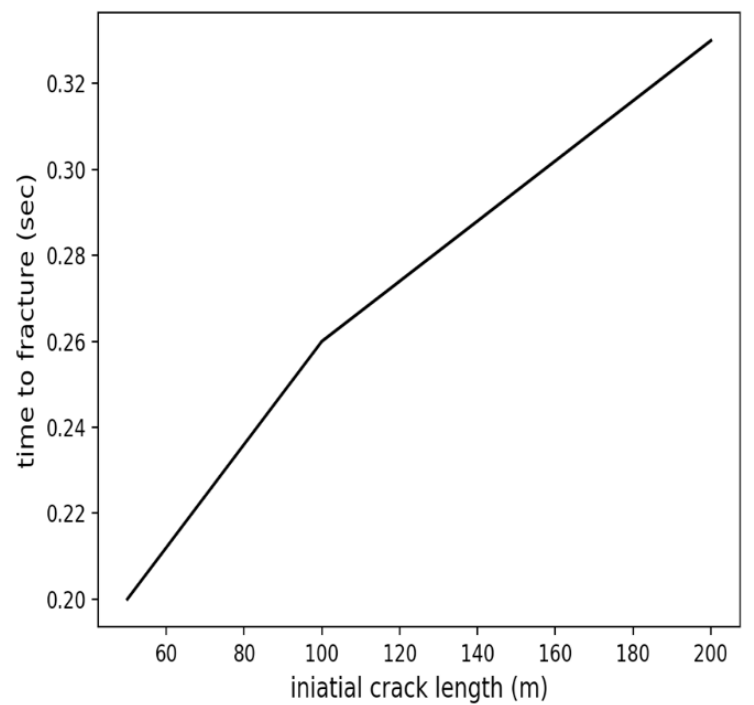

Fig. 7: Time to fracture initiation as a function of the initial crack length. Wellbore pressure is linearly growing from 0 to 500 atm within 8 seconds.

The results presented above are not accounting for tectonic stresses that can be very high and dependent on depth and depletion due to well production. Possible value of tectonic stresses in the direction normal to the direction of the crack is $440 \mathrm{~atm}$, which is equal to $4.458 \mathrm{e} 7 \mathrm{~Pa}$. Figure 8 is plotting time to fracture initiation in the case of tectonic stresses taken into account. As follows from the presented figure, accounting for tectonic stresses can significantly affect predicted time to fracture initiation for fracture at the tip of the existing crack. 
Time at crack initiation for different pressure growth rates

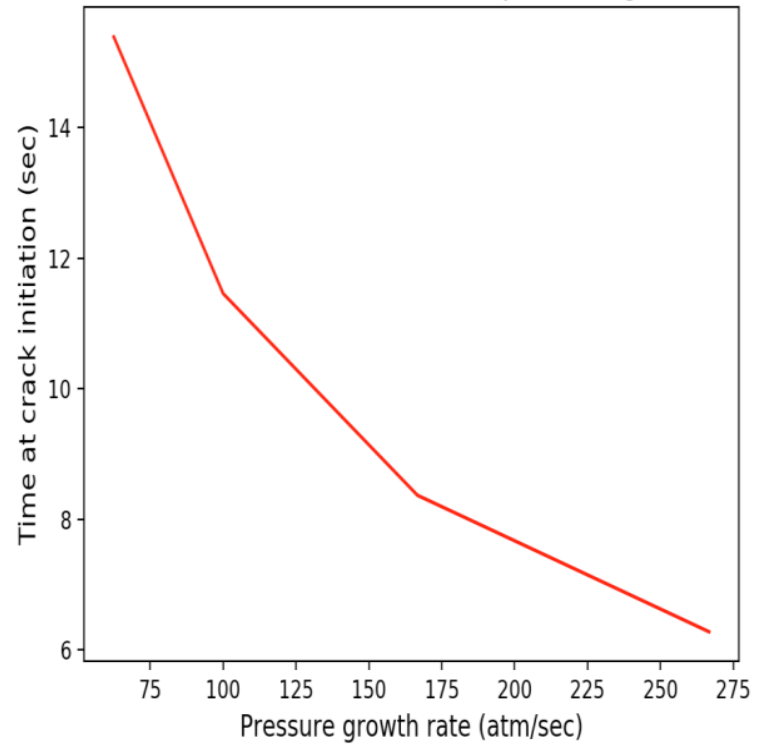

\section{Stressed State Surrounding the Wellbore}

Another possible scenario consists in initiation of new fracture in the region adjacent to the wellbore. In order to study this possibility numerical approaches should be applied. In this work finite element method (FEM) was utilized. Solution was received for 2D problem for a wellbore and a crack of initial hydraulic fracture in an extent domain (to minimize the influence of the boundary). It is supposed that the media is linear elastic. Usual meshing techniques were used to mesh the domain and for this reason mesh is not presented. Stress histories received from the solution of (3)-(9) were applied at the crack faces. In order to verify the numerical scheme, the received time dependencies for stress intensity factor in the tip of the crack were compared to the ones previously computed using the analytical approach. It was found that numerical predictions are in a very good coincidence with the analytical solution. Typical contour plots for received stresses are presented in figure 9 .

Fig. 8: Time to initiation of fracture at the tip of the crack as a function of pressure growth rate. Crack length is $100 \mathrm{~m}$.

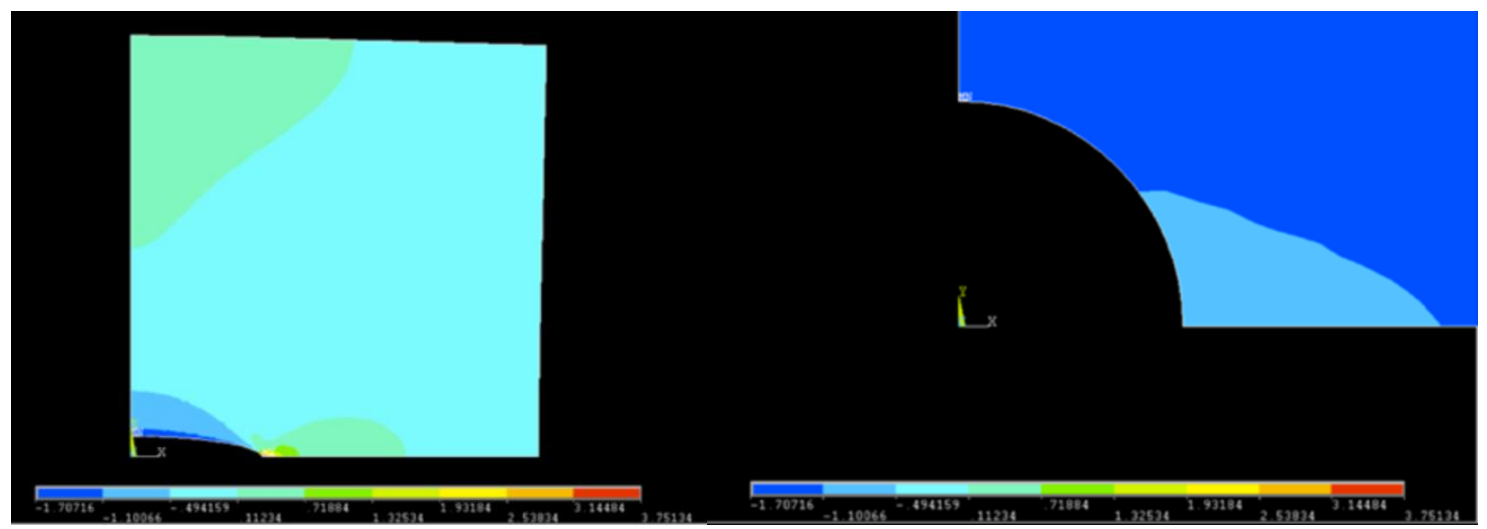

Fig. 9: Typical stressed state for numerical solution.

Using the developed numerical approach stressed state at the region surrounding the crack tip was studied for the range crack lengths and pressure growth rates typical for refract treatments (see table 1). It was found that for all of the studied cases circumferential stresses at the region surrounding the wellbore are compressive. For some cases, very small tensile stresses are developed for times close to pressure growth initiation but the amplitudes of these stresses are orders of magnitude lower comparing to the ones needed to develop fracture in the rock material. Accounting for dynamic effects of inertia (including wave propagation) and introduction of tectonic stresses is not significantly affecting the situation.

\section{Conclusions}

An approach for simulation of refracture treatment on vertical wells is presented. Possibility to evaluate stress intensity factor for the tip of the crack created during previous hydraulic fracturing treatments is demonstrated. The approach is also predicting time at which initiation of fracture should be expected. These estimations can be compared to results of real refracturing treatments where the instance of fracture initiation can be registered (by the registration of pressure drop). Studies of stressed state of the region surrounding the wellbore had shown that within the framework of the developed model, without further assumptions, it is not possible that new fracture will be initiated in this region.

\section{Acknowledgments}

The work was financially supported by the Ministry of Science and Higher Education of the Russian Federation in the framework of the Federal Program "Research and Development in the Priority Areas of Development of the Russian Scientific and Technical Complex for 2014-2020", Activity 1.2., Subsidy Agreement № 14.575.21.0146 of 26.09.2017. Unique project identifier: RFMEFI57517X0146.

\section{References}

[1] Foda, S. (2015). Refracturing: Technology and Reservoir Understanding are Giving New Life to Depleted Unconventional Assets. Journal of Petroleum Technology, 67(07), 76-79.

[2] Vincent, M. (2011). Restimulation of unconventional reservoirs: when are refracs beneficial?. Journal of Canadian Petroleum Technology, 50(05), 36-52.

[3] Asala, H. I., Ahmadi, M., \& Taleghani, A. D. (2016, September). Why re-fracturing works and under what conditions. In SPE Annual Technical Conference and Exhibition. Society of Petroleum Engineers.

[4] Zhang, G. Q., \& Chen, M. (2010). Dynamic fracture propagation in hydraulic re-fracturing. Journal of Petroleum Science and Engineering, 70(3-4), 266-272.

[5] Jayakumar, R., Boulis, A., Araque-Martinez, A., \& Rai, R. (2013). A Systematic Study for Re-fracturing Modeling under Different Scenarios in Shale Reservoirs. Paper SPE, 165677, 20-22. 
[6] Bear, J. (2013). Dynamics of fluids in porous media. Courier Corporation

[7] Carter, R. D. (1957). Derivation of the general equation for estimating the extent of the fractured area. Appendix I of "Optimum Fluid Characteristics for Fracture Extension," Drilling and Production Practice, GC Howard and CR Fast, New York, New York, USA, American Petroleum Institute, 261-269.

[8] Crank, J., \& Nicolson, P. (1947, January). A practical method for numerical evaluation of solutions of partial differential equations of the heat-conduction type. In Mathematical Proceedings of the Cambridge Philosophical Society (Vol. 43, No. 1, pp. 50-67). Cambridge University Press.

[9] Bertram Broberg, K. (1999). Cracks and Fracture, ACADEMIC PRESS INC, United States.

[10] Zehnder, A. T. (2012). Fracture Mechanics, Springer Science+Business Media B.V., Springer Metherlands.

[11] Gallegos, T. J., Varela, B. A., Haines, S. S., \& Engle, M. A. (2015) Hydraulic fracturing water use variability in the United States and potential environmental implications. Water Resources Research, 51(7), 5839-5845

[12] Barati, R., \& Liang, J. T. (2014). A review of fracturing fluid systems used for hydraulic fracturing of oil and gas wells. Journal of Applied Polymer Science, 131(16).

[13] Skoumal, R. J., Brudzinski, M. R., \& Currie, B. S. (2015). Earthquakes induced by hydraulic fracturing in Poland Township, Ohio. Bulletin of the Seismological Society of America, 105(1), 189-197.

[14] Atkinson, G. M., Eaton, D. W., Ghofrani, H., Walker, D., Cheadle, B., Schultz, R., ... \& Liu, Y. (2016). Hydraulic fracturing and seismicity in the Western Canada Sedimentary Basin. Seismological Research Letters, 87(3), 631-647.

[15] Williams, L., Macnaghten, P., Davies, R., \& Curtis, S. (2017). Framing 'fracking': Exploring public perceptions of hydraulic fracturing in the United Kingdom. Public Understanding of Science, 26(1), 89-104.

[16] Guo, T., Zhang, S., Qu, Z., Zhou, T., Xiao, Y., \& Gao, J. (2014). Experimental study of hydraulic fracturing for shale by stimulated reservoir volume. Fuel, 128, 373-380.

[17] Elliott, E. G., Ettinger, A. S., Leaderer, B. P., Bracken, M. B., \& Deziel, N. C. (2017). A systematic evaluation of chemicals in hydraulic-fracturing fluids and wastewater for reproductive and developmental toxicity. Journal of Exposure Science and Environmental Epidemiology, 27(1), 90.

[18] Hyman, J. D., Jiménez-Martínez, J., Viswanathan, H. S., Carey, J. W., Porter, M. L., Rougier, E., ... \& Lei, Z. (2016). Understanding hydraulic fracturing: a multi-scale problem. Phil. Trans. R. Soc. A, 374(2078), 20150426. 